\title{
Six Sigma and the application perspectives of various industries: A bibliometric analysis
}

\author{
Kevin Luis Mendoza-Loyo, Sergio Vázquez-Rosas, Emma Isabel Caballero- \\ López, Uriel Alejandro Hernández-Sánchez
}

Ingeniería en Mantenimiento Industrial, Universidad Tecnológica del Centro de Veracruz, Veracruz, México

Received: 14 Nov 2020; Received in revised form: 07 Dec 2020; Accepted: 15 Dec 2020; Available online: 30 Dec 2020 C2020 The Author(s). Published by Infogain Publication. This is an open access article under the CC BY license (https://creativecommons.org/licenses/by/4.0/).

\begin{abstract}
In recent years, quality in companies has become a priority issue which, according to the organization, is a matter of very little investment and dedication in the production lines, so a quality tool can be the solution to this problem. The present research work is to demonstrate the state of the art on Six Sigma and the perspectives in several industries through a bibliometric analysis using Bibliometrix. A database from Scopus is used, which includes a total of 857 articles in a time span from 2016 to 2020. From the results obtained, some characteristics of the articles are illustrated and analyzed (keywords, main authors, country of origin, main journals, scientific production and collaborative networks). The results obtained from the analysis show the existence of an exponential increase trend on Six sigma, being the basis for improving the quality of the processes.
\end{abstract}

Keywords - Six sigma, Lean six sigma, Bibliometrix.

\section{INTRODUCTION}

Six Sigma is defined as a methodology for the pursuit of continuous improvement in the field of Quality Management, which goes beyond the reduction of defects and emphasizes process improvement. It emerged as an innovative alternative in the organizations and became the focus of attention of general and quality managers.

Six Sigma, on the other hand, is a tool that is practiced in the field of management to address complex organizational problems that require extensive data analysis, confirmation of results and validation of real long-term benefits. In other words, it offers more guarantees to management to solve the deep-seated and complex performance problems of their organizations.

The objective of this article is to analyze the state of the art on the subject, through various databases to determine the impact of this quality tool in various industries, addressing aspects such as identification of countries, most cited publications, main authors on the subject.

\section{LOCALIZED DEFINITIONS OF SIX SIGMA IN THE LITERATURE}

Several definitions of Six Sigma were found in various publications and are shown in Table 1. This allows us to observe how Six Sigma is approached by different authors in different approaches from the application theme, methodology, philosophy and implementation models.

Table 1. Six Sigma Definitions

\section{Authors Definition}

O.M. Ikumapayi, E.T. Six Sigmas is a profit Akinlabi, F.M. Mwema, maximization technique O.S. Ogbonna (2020) achieved by meeting the need of the consumer.

Six Sigma is a

M. T. Pereira, M. Inês Bento, L. P. Ferreira, J. C. Sá, F. J. G. Silva (2019) methodology that aims to reduce process variation, reduce manufacturing costs and improve customer satisfaction.

Six Sigma is aimed at two

Eva Nedeliaková, levels of quality, potential and actual quality, the 
Vladimíra Štefancová, difference between them is Štefan Kudláč (2017) a waste.

Six Sigma is a data-driven methodology that focuses on reducing variation. In Erdil, NO, Aktas, CB y terms of statistics, Six Arani, OM (2018)

Kaswan, MS y Rathi, R. (2020). Sigma implies process output with no more than 3.4 defects per million.

Sigma is a statistically based approach that works on a project-by-project basis and incorporates qualified tools that can complement the GL methodology.

Silich et al., 2012; Singh y Khanduja, 2014

Erdil, NO, Aktas, CB y Arani, OM (2018)

The idea behind Six Sigma is that, if imperfections can be measured, then the solution can be planned to eliminate them.

Six Sigma is different from other approaches and organizational structures. In Six Sigma organizations, different degrees, authorities, and responsibilities are given to staff depending on the type of education they have received.

Kaswan, MS y Rathi, R. Six Sigma is an organized, (2020).

Silich et al., 2012; Singh y Khanduja, 2014

parallel-meso structure to reduce variation in organizational processes through the use of improvement specialists, a structured approach and performance metrics to achieve strategic objectives

The idea behind Six Sigma is that, if imperfections can be measured, then the solution can be planned to eliminate them

Ertürk, M., Tuerdi Six Sigma is different from (Maimaitiaili. Tuerdi), M., other approaches and y Wujiabudula, A. (2016) organizational structures. In Six Sigma organizations,
Zu et al (2008)

different degrees, authorities, and responsibilities are given to staff depending on the type of education they have received

Cherrafi, A., Elfezazi, S., Six Sigma is an organized, Chiarini, A., Mokhlis, A. y parallel-meso structure to Benhida, K. (2016) reduce variation in organizational processes through the use of improvement specialists, a structured approach and performance metrics to achieve strategic objectives

The objectives of Six Sigma are to improve process performance and achieve high levels of quality by investigating and eliminating the root causes of defects and minimizing process and product variability

Chen, S., Fan, S., Xiong, J. The five stages of the Six y Zhang, W. (2017). Sigma DMAIC improvement model (define, measure, analyze, improve, control) is the central Six Sigma management system based on the JMP / SAP system.

Laureani, A. y Antony, J. Lean Six Sigma is a (2015).

business improvement methodology that aims to maximize shareholder value by improving quality, speed, customer satisfaction and costs.

Niñerola, A., Sánchez- Six Sigma is a business Rebull, M.-V., y process strategy that Hernández-Lara, A.-B. combines statistical and (2019 management approaches.

Schroeder, Linderman, It is based on the principle Liedtke y Choo, (2008) of measurement, monitoring and control of processes and provides an organizational structure for continuous improvement. 
Nourelfath, $\quad$ M., Six Sigma is a quality Aldowaisan, T. y Hassan, philosophy and J. (2016). $\quad$ methodology that aims to achieve operational excellence and delighted customers. The cost of poor quality depends on the sigma quality level and its corresponding failure rate

Laureani, A. y Antony, J. The term 'Lean Six Sigma' (2017).

Rinawati, DI, Andini, AR y The sigma measurement Sari, DP (2019). scale $(\sigma)$ is correlated with characteristics such as defects per unit, parts per million defects and the probability of failure

Pavlickova, M. y The Six Sigma method is a Bogdanovska, G. (2016). complete and flexible system to achieve, determine and maximize business success. Six Sigma is based on understanding the needs and expectations of customers, using data and statistical analysis, resulting in the improvement and creation of new business processes, production and work

Cardiel Ortega, JJ, Baeza Serrato, R. y Lizárraga Morales, RA (2017)
The Six Sigma methodology is widely used in business to improve quality, increase productivity and reduce costs, which impacts business improvement
Rathilall, R. y Singh, S. The intention of the Six (2018) Sigma technique is to eliminate process variation and strive for defect-free products. It is associated with the acronym DMAIC which stands for Define, Measure, Analyze, Improve and Control. This serves as the basis and the systematic five-step problem solving methodology followed to find the causes of variation in system processes

Navas, RKB, Akash, RP, Six - sigma is a quality Sathish, G. y Azharudeen, management strategy, JM (2016)

which can be used to achieve the goal of engineering education.

It provides a scientific and statistical basis for the evaluation of the quality of all processes by measuring the level of quality

Parmar, PS y Desai, TN The SS methodology aims (2020). to eliminate the root causes of process variations, and seeks to reduce defects by improving the process

Source: Own elaboration

The Six Sigma quality indices for the evaluation of the quality levels associated with the unilateral, bilateral and Finally, it presents three cases and numerical experiments to demonstrate the practical applicability of the proposed method, that method was the use of the multiple characteristics process capability analysis chart to determine if the quality of the process is sufficient to reach the quality level and meet the client's requirements ( Cudney et al., 2020; Navas et al. 2017; Sony et al., 2020). Unfortunately, the other methods proposed in these studies can only identify the range of quality level that a process achieves ( Nourelfath et al., 2016; Foster, 2007; Nourelfath et al., 2016).

The integrating Lean and Six Sigma tools as a unified approach to continuous improvement and developing a Lean Six Sigma framework for selected organizations in South Africa where quantitative research methods were 
adopted and therefore the results of the study showed that the organizations had a very low success rate in adopting Lean and Six Sigma as stand-alone systems, as they found it difficult to sustain the transition from theory to practice (Allen, 2018; Parmar \& Desai, 2020; Rathilall \& Singh, 2018).

The integration of the ecological approach and the Six Sigma approach to overcome limitations, and evaluate the performance of the ecological approach. Measurement system analysis and instrument control are used as a methodology to measure process variations in order to decrease unfavorable ecological impacts of companies' products or services, while improving environmental efficiency (Sagnak \& Kazancoglu, 2016; Waurick, 2014).

Related the automotive field presents a creative solution to improve an assembly process in an automotive company, through the use of the statistical thinking methodology and DMAIC Six Sigma, so it resulted that the introduction of the SS methodology provides innovative quality improvements in a reasonable time (Pereira et al., 2019; Pugna et al., 2016; Rinawati et al., 2019).

\section{METHODOLOGY}

For the accomplishment of this article, it was divided in three phases; these will be detailed in chronological form next: In the first stage, different reliable sources of information were gathered for their respective consultation on the related topic and the evaluation of such information from the articles related to Six Sigma. The databases used for consultation: Scopus, SpringerLink and Taylor \& Francis, these sources were used for their large number of articles related to this topic and for the impact of these.

In the second phase, we started with the collection of information from the analyzed papers and submitting our database generated from the review. The data was loaded into Bibliometrix to start with the bibliometric analysis and observe the behavior of the construct (Aria, \& Cuccurullo, 2017).

In the third stage we proceeded to perform a brief analysis with the information provided by Bibliometrix and understand the state of the art of Six Sigma and its impact on the industries today.

By gathering the 2016-2020 information on Six Sigma and Lean Six Sigma information in the Scopus database, the following information was obtained. Figure 1 shows the annual scientific production of articles related to Six Sigma and its behavior in the study period. A total of articles on the subject already mentioned were obtained in their respective year, with 2019 being the most active year for the authors with a total of 857 articles published.

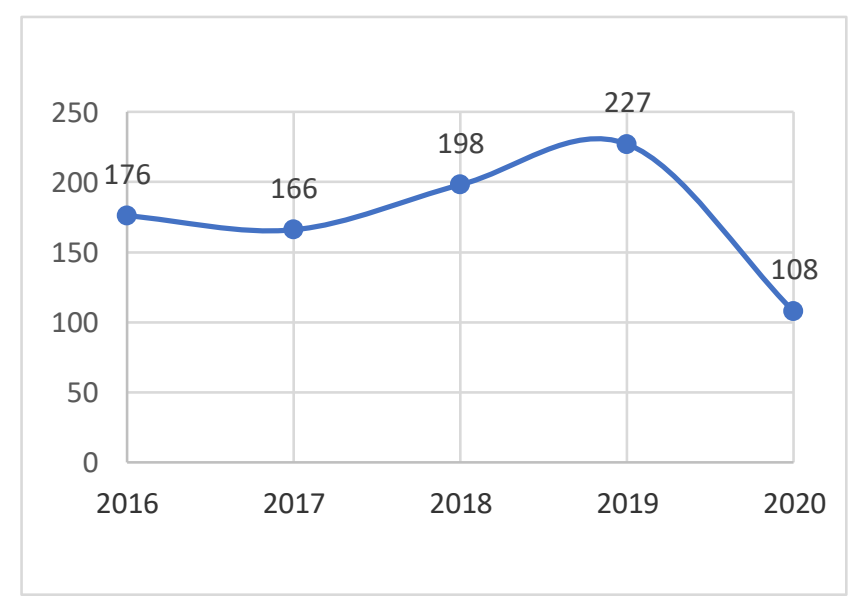

Fig. 1 Scientific production

\section{RESULTS}

On the other hand, a comprehensive review found that 2016 was the year with the highest average number of citations per article and per year. Being this the year with the highest number of citable years; it should be emphasized that the same year was the penultimate year with the lowest number of articles published in the study period. In addition, it should be mentioned that the year with the lowest number of articles published (2017) is the one that is closest to 2016 on average, both by article and by year.

As can be seen in figure 2 , the most cited countries in the period 2016-2020 the one that presents the greatest interest and development of Six Sigma reference articles is India with a total of 192 citations up to the moment of data collection, it is worth mentioning that the second most cited country (Morocco) with a total of 146 citations is the country with the highest average of citations with 48,667; much higher than the average of India with 5,647. 


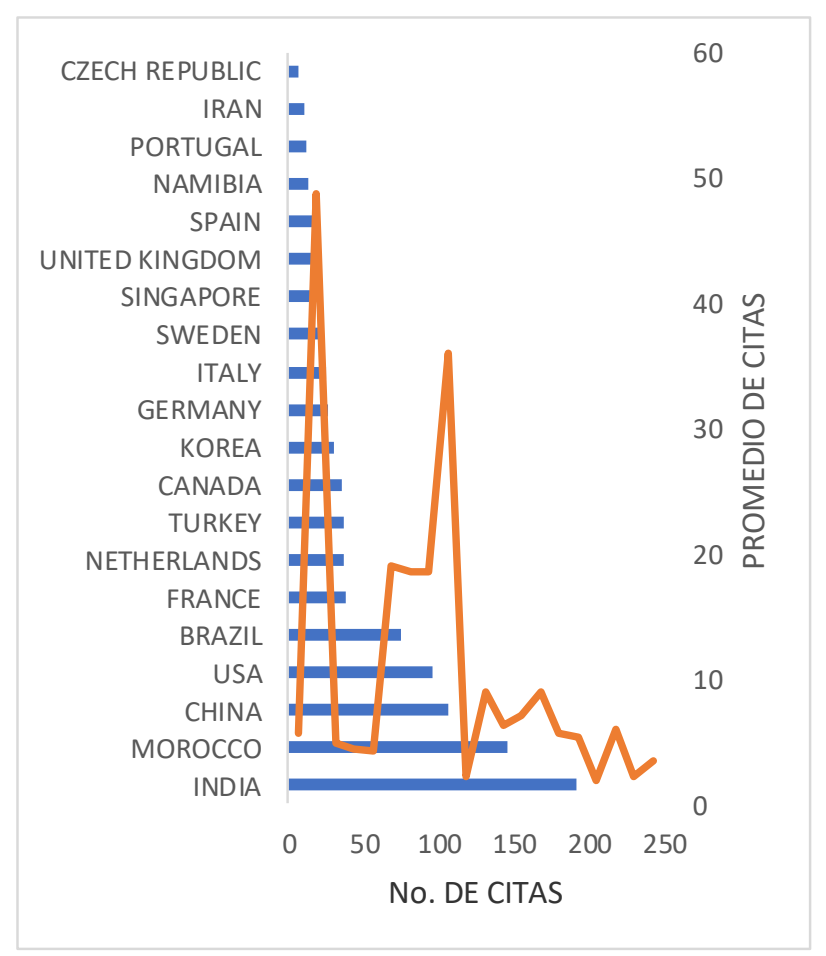

Fig. 2 Most cited countries

Figure 3 shows the countries with a greater interest in development and research on the subject, being India, which is observed a total of 34 articles published in the period between 2016-2020, followed by the equality between 2 world powers that are the United States and China with 22 articles each one, giving to speculate that the interest by this subject has potential by the interest of great powers like by the developing countries, being the European and American continent with greater presence in the subject.

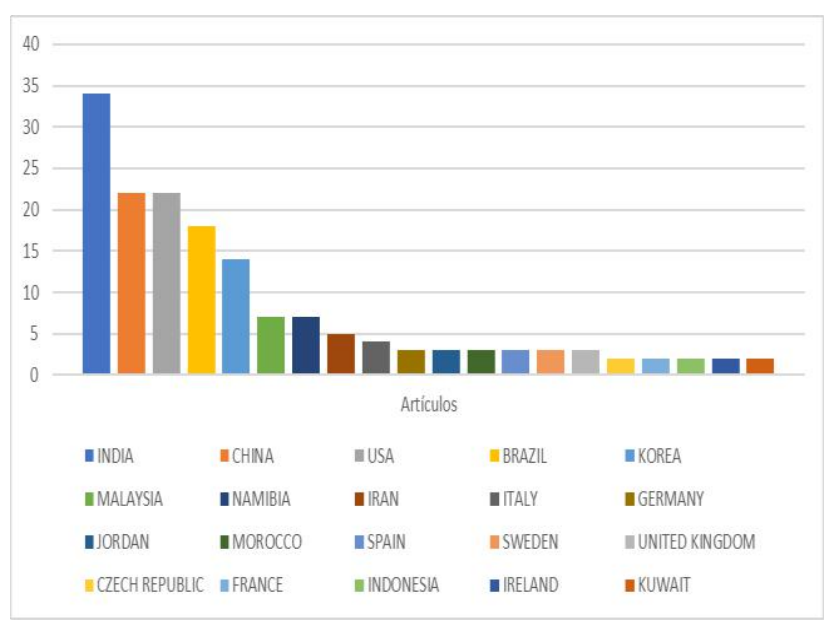

Fig. 3 Countries with a greater interest in development
In order to illustrate the most cited sources in the period between 2016-2020, figure 4 shows the International Lean Six Sigma Magazine as the largest producer of reference material with a total of 86 registered articles published, this being a magazine dedicated to the particular topic. With just over half (48) of the articles published, there is an equality between the magazine of Total Quality Management and Business Excellence and the International Journal of Quality Management and Reliability, being this because they are related to the management and administration itself that is part of Six Sigma.

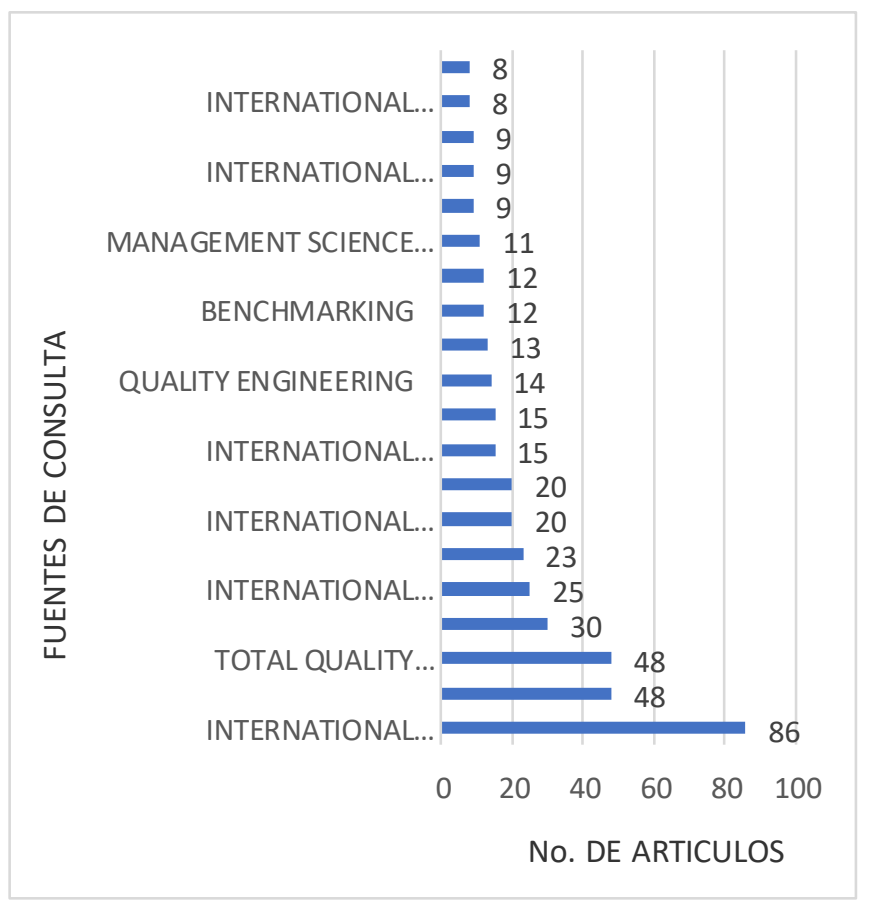

Fig. 4. Most relevant sources

\section{CONCLUSION}

Six Sigma is a methodology for improvement in the field of Quality Management. It has been successfully applied in many companies, however, in other companies when applying it, the same results were not found. The successes and/or failures are generally attributed to many aspects that are ignored during the implementation phase. Organizations behave differently in different circumstances, times and places.

The objective of this work was to identify those aspects related to the publications on the subject, the authors who carried out works on it and the importance or relevance in different countries of the world, as well as the analysis of its history at the time of its implementation and that subsequently affect the resolution of those problems that arise as Six Sigma improvement projects. 
On the other hand, this article will serve as a contribution to the new generations of students to promote research interest in the subject, as well as the realization of projects with this tool.

It should be noted that with the research, the implementation of such tool requires a good vision of senior management, participation and commitment of all levels of an organization, appropriate strategies based on practical experiences, good training in the use of statistical tools and dissemination of knowledge in statistical methods at all levels of the company, effective coordination through proper project management, quality leadership, motivation at all levels and teamwork of managers and other staff of a company.

\section{REFERENCES}

[1] Adams, C. W., Gupta, P., \&amp; Wilson, C. E. (2003). The History of Six Sigma. Six Sigma Deployment. https://doi.org/10.1016/B978-0-7506-7523-9.50022-2

[2] Allen, T. T. (2018). Introduction to engineering statistics and lean six sigma: Statistical quality control and design of experiments and systems. In Introduction to Engineering Statistics and Lean Six Sigma: Statistical Quality Control and Design of Experiments and Systems. https://doi.org/10.1007/978-1-4471-7420-2

[3] Aria, M. \& Cuccurullo, C. (2017). bibliometrix: An R-tool for comprehensive science mapping analysis, Journal of Informetrics, 11(4), pp 959-975, Elsevier, DOI: 10.1016/j.joi.2017.08.007

[4] Bloj, M.-D., Moica, S., \& amp; Veres, C. (2020). Lean Six Sigma in the Energy Service Sector: A Case Study. Procedia Manufacturing. https://doi.org/10.1016/j.promfg.2020.03.051

[5] Chen, K. S., Chen, H. T., \&amp; Chang, T. C. (2017). The construction and application of Six Sigma quality indices. International Journal of Production Research. https://doi.org/10.1080/00207543.2016.1246763

[6] Condé, G. C. P., \&amp; Martens, M. L. (2019). Six sigma project generation and selection: literature review and feature based method proposition. Production Planning and Control. https://doi.org/10.1080/09537287.2019.1706196

[7] Costa, J. P., Lopes, I. S., \&amp; Brito, J. P. (2019). Six Sigma application for quality improvement of the pin insertion process. Procedia Manufacturing. https://doi.org/10.1016/j.promfg.2020.01.126

[8] Costa, L. B. M., Godinho Filho, M., Fredendall, L. D., \&amp; Ganga, G. M. D. (2020). The effect of Lean Six Sigma practices on food industry performance: Implications of the Sector's experience and typical characteristics. Food Control. https://doi.org/10.1016/j.foodcont.2020.107110

[9] Cudney, E. A., Venuthurumilli, S. S. J., Materla, T., \&amp; Antony, J. (2020). Systematic review of Lean and Six Sigma approaches in higher education. Total Quality Management and

Business

Excellence.

https://doi.org/10.1080/14783363.2017.1422977

[10] Foster, S. T. (2007). Does Six Sigma Improve Performance? Quality Management Journal. https://doi.org/10.1080/10686967.2007.11918043

[11] Laureani, A., \&amp; Antony, J. (2019). Leadership and Lean Six Sigma: a systematic literature review. In Total Quality Management and Business Excellence. https://doi.org/10.1080/14783363.2017.1288565

[12] Navas, R. K. B., Akash, R. P., Sathish, G., \&amp; Azharudeen, J. M. (2017). Education: Examination Result Analysis Using Six Sigma - A Case Study. https://doi.org/10.1109/mite.2016.056

[13] Nourelfath, M., Aldowaisan, T., \&amp; Hassan, J. (2016). Evaluating Six Sigma failure rate for inverse Gaussian cycle times. International Journal of Production Research. https://doi.org/10.1080/00207543.2016.1190880

[14] Parmar, P. S., \&amp; Desai, T. N. (2020). Evaluating Sustainable Lean Six Sigma enablers using fuzzy DEMATEL: A case of an Indian manufacturing organization. Journal of Cleaner Production. https://doi.org/10.1016/j.jclepro.2020.121802

[15] Pereira, M. T., Inês Bento, M., Ferreira, L. P., Sá, J. C., \&amp; Silva, F. J. G. (2019). Using Six Sigma to analyse Customer Satisfaction at the product design and development stage. Procedia Manufacturing. https://doi.org/10.1016/j.promfg.2020.01.124

[16] Pugna, A., Negrea, R., \& amp; Miclea, S. (2016). Using Six Sigma Methodology to Improve the Assembly Process in an Automotive Company. Procedia - Social and Behavioral Sciences. https://doi.org/10.1016/j.sbspro.2016.05.120

[17] Rathilall, R., \&amp; Singh, S. (2018). A lean six sigma framework to enhance the competitiveness in selected automotive component manufacturing organisations. South African Journal of Economic and Management Sciences. https://doi.org/10.4102/sajems.v21i1.1852

[18] Rinawati, D. I., Andini, A. R., \&amp; Sari, D. P. (2019). Improving quality for plate assembly of drum brake using six sigma method. AIP Conference Proceedings. https://doi.org/10.1063/1.5112407

[19] Sagnak, M., \&amp; Kazancoglu, Y. (2016). Integration of green lean approach with six sigma: an application for flue gas emissions. Journal of Cleaner Production. https://doi.org/10.1016/j.jclepro.2016.04.016

[20] Sony, M., Naik, S., \&amp; Antony, J. (2020). Lean Six Sigma and social performance: A review and synthesis of current evidence. Quality Management Journal. https://doi.org/10.1080/10686967.2019.1689799

[21] Tenera, A., \&amp; Pinto, L. C. (2014). A Lean Six Sigma (LSS) Project Management Improvement Model. Procedia Social and Behavioral Sciences. https://doi.org/10.1016/j.sbspro.2014.03.102

[22] Waurick, T. (2014). Prozessreorganisation mit Lean Six Sigma. In Prozessreorganisation mit Lean Six Sigma. https://doi.org/10.1007/978-3-658-07754-9 